\title{
Effect of Globalization on the Performance of Small and Medium Scale Enterprises in Nigeria
}

\author{
Akyuz Murat ${ }^{1}$, Opusunju Michael Isaac ${ }^{2, *}$ \\ ${ }^{1}$ Department of Business Administration, Nile University of Nigeria, Abuja, Nigeria \\ ${ }^{2}$ Department of Business Administration, Nasarawa State University, Keffi, Nigeria
}

Email address:

murat.akyuz@nileuniversity.edu.ng (A. Murat), opusnjumike @ gmail.com (O. M. Isaac)

${ }^{*}$ Corresponding author

\section{To cite this article:}

Akyuz Mura, Opusunju Michael Isaac. Effect of Globalization on the Performance of Small and Medium Scale Enterprises in Nigeria. American Journal of Environmental and Resource Economics. Vol. 4, No. 4, 2019, pp. 125-131. doi: 10.11648/j.ajere.20190404.12

Received: August 4, 2019; Accepted: September 29, 2019; Published: October 16, 2019

\begin{abstract}
The examined the effect of globalization on the performance of small and medium scale enterprises in Nigeria. The research design adopted for the study is ex-post facto and the population of this is all the small and medium scale enterprises in Abuja. The population of the study is 72838 and was used as the sample size. Globalization was measured by trade openness and small and medium scale enterprise performance was measured by SMEs output. The study covered a period of 32 years from 1986-2018. The statistical tools adopted in this study were descriptive statistics, correlation analysis, unit root test, co-integration and granger causality test. The analysis was conducted using e-view statistical software and the finding indicate that globalization influence the performance of small and medium scale enterprises in Nigeria. The study suggested that Nigerian government of Nigeria should encourage import and export of small and medium scale products and service across border and they should also place little or no restriction on SMEs products and services in order to encourage the SMEs output growth in Nigeria.
\end{abstract}

Keywords: Globalization, Trade Openness, Performance, SMEs and Output

\section{Introduction}

Globalization could be defined in simple terms as the easy access or reach of a certain resource the world over. In this context, globalization is a way of removing trade barriers. Globalization is a phenomenon that no development agenda can afford to ignore. The economic activities are saturated with globalization process and the driving force of his process in small scale business. It is believed that higher degree of globalization in terms trade openness ensures better flow of income from developed countries to their developing counterpart which may influence the SMEs performance in terms of growth. It is equally evident that the latter (especially the ECOWAS Members) have not fully aligned their economies to allow the SMEs investment to stimulate satisfactory growth (9).

Over the years, globalization has been used as a driver to force developing countries to perform in their business and economic sectors such as helping to grow the SMEs sector in
Nigeria. Yet, globalization has not positively influence SMEs performance in Nigeria and also, SMEs sector in Nigeria do not developed since are deteriorating and dying every year with the helped of Nigeria. It is also uncertain whether globalization in terms of trade openness attracted SMEs performance or SMEs performance in Nigeria attracted trade openness.

From the extant literature, studies such as $[2,16,14,15,6$, $8]$ studied the variables in Nigeria but none of studied, used casual effect relation between the variables. The study filled the research gap by using casual effect relationship between the dependent and independent.

The objective of this study is to examine the causal effect of globalization on SMEs performance in Nigeria. The specific objective is to examine the causal effect of trade openness on SMEs performance in Nigeria.

The scope of this study is restricted to the effect of causal effect of globalization on SMEs performance in Nigeria. The period of study is 32 from 1986 to 2018. The period is chosen because Nigerian Government adopted Structural 
Adjustment Programme (SAP) in June, 1986 to prevent an economic crisis in the wake of dropping oil prices and the adoption of SAP led to the emergence of trade liberalization in Nigeria which was accompanied by elimination of import license, removal of foreign exchange and price control to allow Oil and Gas foreign direct investment in Nigeria (25).

The hypothesis is stated below:

$\mathrm{H}_{01}$ : There is no causal effect relationship between trade openness and SMEs output in Nigeria.

\section{Concept of Globalization}

Globalization entails integration of industries, markets, economies, policy-making and culture dispersing a wide geographical area [20]. Thus, globalization describes the process in which national and regional economies have become integrated and inter-dependent through global network trade, immigration, communication and transportation. [19] Globalization has brought about many advantages as well as challenges. For example, globalization encourages producers to benefit from free movement of labor between countries through sharing of skills, ideas and technology. [12]

Globalization is the process of opening up of economies to the outside world to aid trade, fall in physical and other barriers to enhance mobility of goods and factors of production as well as labour force. With the removal of barriers to trade, competition has intensified and has presented both opportunity and challenges to domestic firms to innovate and improve their competitive position [1].

Trade Openness is defined as trade volumes which is exports plus imports as a share of GDP and this to them is a measure of trade openness. ${ }^{6}$ Trade openness' and 'liberalisation' interchangeably in the context of trade. Openness to trade is defined as imports plus exports divide by Gross Domestic Product for the whole economy and separately for three sectors (primary, manufacturing and services) [22].

Trade Openness measures the international competitiveness of a country in the global market. To him, it is use as addition of imports and exports over GDP. ${ }^{4}$ Trade Openness is the outward and inward orientation in country's economy [11].

Trade ppenness is the removal of obstacles to free trade (obstacles such as quotas, nominal and effective rates protection and exchange controls). ${ }^{3}$ Trade liberalization involves the elimination of non-tariff barriers to imports, the rationalization and reduction of tariffs, the institution of market determined exchange rate and removal of fiscal disincentives and regulatory deterrents to exports. The motive is to create competitive atmosphere between local and foreign industries [3].

Trade Openness is conceptualized as the free market economy where Government allowed little or no restriction and ensured such policies as import substitution, export promotion and checkmate the gross domestic product as a percentage of these policies. Trade openness encompasses some policies which are highlighted below.

Import Substitution refers to domestic production of manufactured goods for domestic markets. It involves processing of raw materials and setting up of manufacturing factories to produce locally certain manufactured goods which were originally imported by a country thereby saving the country from importation of such commodities into the local markets. To get the home industries started and make them survive, it requires the imposition of protective tariffs, import quotas and exchange controls to protect the home industries from foreign competitors by making the entry of foreign goods expensive. ${ }^{24}$

The indigenization policy started in 1972 with "the Nigerian Enterprises Promotion Decree" (NEPD). The decree imposed several restrictions on FDI entry. As a result, some 22 business activities were exclusively reserved for Nigerians, including advertising, gaming, electronics manufacturing, basic manufacturing, road transport, bus and taxi services, the media and retailing and personal services. Foreign investment was permitted up to 60 per cent ownership and provided that the proposed enterprise had, based on 1972 data, share capital of N200,000 $(\$ 300,000)$ or turnover of N500,000 (\$760,000).

Export promotion otherwise described as outward oriented industrialization, involves domestic production of manufactured goods for export and it is Governments deliberate efforts to expand the volume of a country's exports through export incentives and other means in order to generate more foreign exchange and improve the current account of the balance of payment $[23,17]$.

Exports promotion trade policy and intensification of local raw materials utilization for industrial production began in 1981. Balance of payments however worsened with increase in importation and collapse in world oil prices. This led to the Economic Stabilization (Temporary Provisions) Act in April 1982, where tariffs on 49 items were raised, prohibition imposed on gaming machines and frozen poultry. 29 commodities have general import license removed and replaced with specific license using pre-shipment inspection. 1983-1985 witnessed 152 items introduced under specific import license, and stringent foreign exchange regulations. This was to meet the trade policy objective of protecting domestic industries and reducing dependence on imports. This was expected to reduce unemployment level and generate revenues. Raw materials and intermediate capital goods tariffs were scaled down [5].

Gross Domestic Product is the market value of all final goods and services produced within a country in a given period. It is often considered an indicator of growth and standard of living for a country. Also, Gross Domestic Product (GDP) measures the value of a country's overall goods and services at market prices, without including income from abroad. GDP is the market value of goods and services produced within a selected geographic area (usually a country) in a selected interval in time (often a year) [18]. 


\subsection{Concept of Performance}

Performance is the function of the ability of an organization to gain and manage the resources in several different ways to develop competitive advantage [13]. There are two kinds of performance, financial performance and non-financial performance; and financial performance emphasizes on variables related directly to financial report. The term is also used as a general measure of a firm's overall financial health over a given period of time and can be used to compare similar firms across the same industry or to compare industries or sectors in aggression [13].

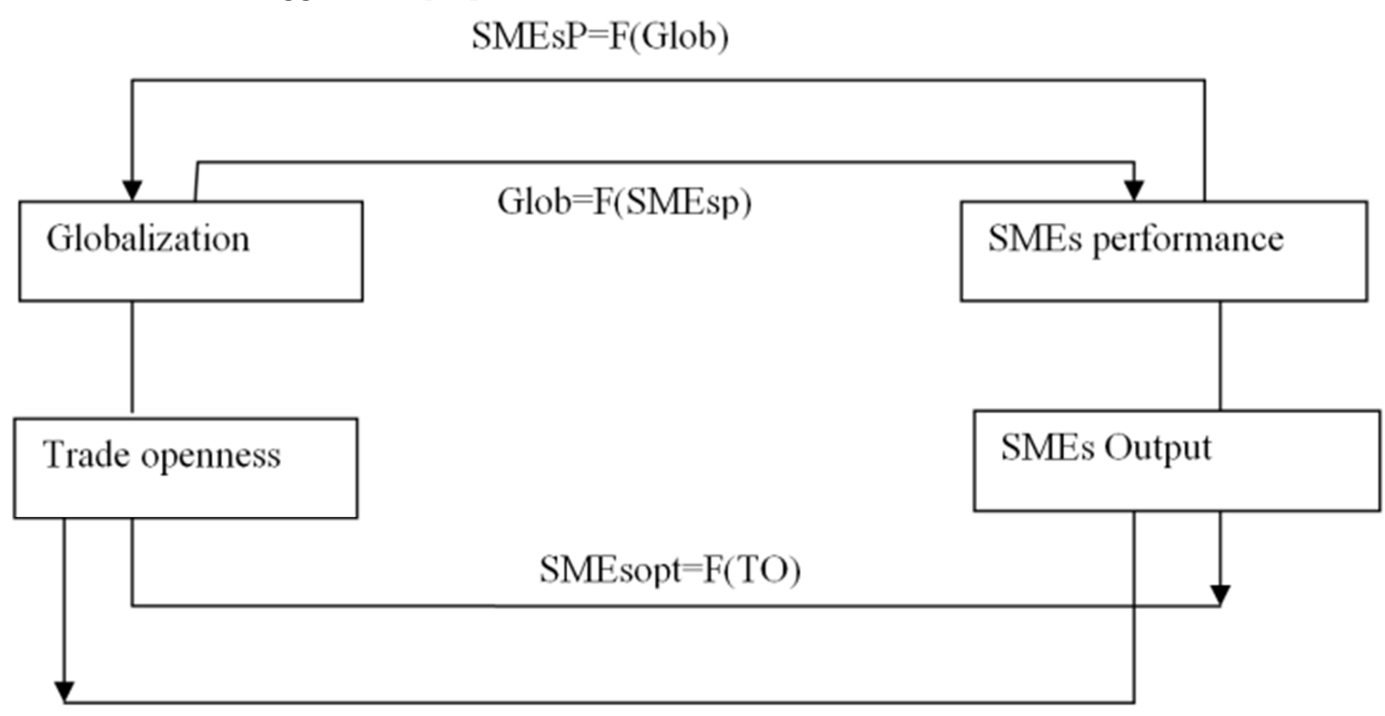

$\mathrm{TO}=\mathrm{F}($ SMEsopt $)$

Figure 1. Conceptual Framework.

Researchers Model

\section{Empirical Studies}

A study was conducted to determine whether globalization has had an impact on SMEs in emerging economies in the context of Zambia. A better understanding on impacts of globalization should help stakeholders to direct their scarce resources to combat on what might impinge their success. The study utilized the mixed method technique combining qualitative and quantitative research methods. The sample size comprised 104 participants across fifty (50) SMEs operating in Zambia. The study found that globalization has affected these SMEs negatively [6].

A similar study addressed the effect of globalization on small and medium enterprises (SMEs) performance in Nigeria. The study adopts an ex post-facto type of descriptive research design. In carrying out this study, the secondary statistics data was used. Data was extracted from CBN bulletin on relevant information which depicts globalization and its effect on SMEs performance in Nigeria. A cointegration model was used to investigate the effect of globalization on SMEs performance in Nigeria. To capture the activities of globalization, three proxies were used to capture the activities of globalization; they include interest

\subsection{Concept of Small and Medium Scale Enterprises}

The Central Bank of Nigeria, in its 2005 guideline on Small and Medium Enterprise Investment Scheme (SMEIS), described SME as any enterprise with a maximum asset base of 200million naira (excluding land and working capital) with no lower or upper limit of staff. Using quantitative indices alone to define SMEs have proven unsatisfactory in many respects. This is because such indices are characterized by periodic alterations due to inflation and thus can sometimes be misleading. 
alleviation. Study further reveals that globalization contributes $40.96 \%$ to poverty alleviation. The study concludes that globalization has boosted the performance of SMEs in Nigeria positively [15].

In Pakistan, a study investigated the Globalization impact on the SMEs export by using Computable General Equilibrium model. The main objectives of this research are to provide detailed overview of economic reforms in the last decade by using the General Equilibrium Model. Data were collected from 300 SMEs business exports in Pakistan by using simple random technique. Structural questionnaire is used as a basic tool for measuring export potential. Data from developing countries were collected through secondary sources and data were analysis by using Gem-Software. It was revealed that from last decade, globalization has positively revolutionized the SMEs export business the economy of Pakistan. The Global trade analysis Purdue (GTAP) model is used to analyze the possible impact of Globalization on Pakistan's economy in a multi-country, multi-sector applied General Equilibrium frame work. After employing the simplified static analysis framework based on simulations reveal that Globalization and FDI have influenced positively on the economy of Pakistan. The general inflation rate is decreased and living standard is increased in urban areas. Employment opportunities are also increasing due to the investment made by the FDI and as for as cultural context is concerned, Pakistani people are more reluctant to reduce the traditional cultural barriers. On the contrary side, other consumer items like leather-made and cotton-made garments will expand after the FTA and consumer surplus will increase. This perspective enables us to identify new challenges in the global economy and to identify the multiple routes through which power and resource inequalities are reproduced within it. More positively, it helps to identify new opportunities and routes to challenging these inequalities [2].

A similar study focused on the influence of globalization on performance of small and medium enterprises in the information and communications technology sector in Kenya. The study employed a cross sectional research design to achieve the objectives. The target population under study was registered ICT companies in Kenya. Of the registered companies $81 \%$ were based in Nairobi of which at least 42 Small and medium sized ICT firms were randomly selected as the sample size. Secondary data was gathered from Journal Publications, Articles, Government and Non-governmental bodies statistics on effect of globalization, library material, ICT journals and reports, media publications and various Internet search engines covering the influence of globalization to SMEs in ICT sector. Primary data was collected from respondents by the use of a questionnaire. The main focus of this study was qualitative research in order to provide holistic understanding of the objective. Descriptive analysis and interpretive approach was used to analyze the data. This made the data more meaningful and illustrative in the process of establishing the influence of globalization on SMEs in ICT sector In Kenya. The study concluded that globalization contributed both positively and negatively on the performance of SMEs in the ICT sector In Kenya [1].

A study determined the influence of trade liberalisation on innovative performance of SMEs in the two largest economies in West Africa - Nigeria and Ghana. This study utilized data from both primary and secondary sources. The six states in Southwest Nigeria, and Ashanti and Greater Accra regions that house more than $50 \%$ and $70 \%$ of SMEs in Nigeria and Ghana respectively were purposively selected for the study. In order to have a representation of each business line covered in this study, stratified sampling technique was used in selecting SMEs in four major business areas, namely; manufacturing, trade and distribution, service, and agro-allied business. Questionnaire and interview were employed to obtain primary data from the selected SMEs in the study areas. Altogether, 1,247 and 626 SMEs were selected in southwest Nigeria and the two regions in Ghana respectively using simple random sampling technique. Data collected were analyzed using both descriptive and inferential statistics. The results established that there was a significant positive relationship between trade liberalisation and product innovation $(r=0.071 ; \rho=0.026)$, marketing innovation $(r=0.095 ; \rho=0.003)$, and organisational innovation $(r=0.077 ; \rho=0.015)$ in the selected Nigerian SMEs. However, only process innovation $(r=0.220 ; \rho=$ 0.000) showed significant association with trade liberalisation in the selected SMEs in Ghana. The study concluded that trade liberalisation is crucial for the survival and innovative performance of sub Saharan African countries' SMEs in the face of intense competition and challenges of globalisation and economic liberalization [8].

\section{Trans-formationalism Theory}

This hypothesis was produced by David Held. His partners have explained this hypothesis. As indicated by them, globalization' reflects expanded interconnectedness in political, financial and social issues over the world making a "common social space". Given this interconnectedness, globalization might be characterized as "a procedure (or set of procedures) which exemplifies a change in the spatial association of social relations and exchanges, communicated in transcontinental or interregional streams and systems of movement, collaboration and power." While there are numerous meanings of globalization, such a definition looks to unite the numerous and apparently opposing hypotheses of globalization into a "thorough systematic structure" and "proffer an intelligible chronicled account". Held and McGrew's explanatory system is built by building up a three section typology of hypotheses of globalization comprising of "hyper-globalist," "doubter," and "transformationalist" classes.

\section{Research Methodology}

The study used ex-post facto research design and this is because the study tried to find out the cause and effect relationship between the variables. The reason is because ex- 
post facto research design is a systematic empirical inquiry in which the researcher does not have direct control of variables because their manifestations have already occurred and they are inherently not manipulated. The population of this study comprises of allthe registered SMEs in Nigeria. According to Smedan and national bureau of statistics collaborative survey (2013), the population is72838 SMEs in Nigeria. The data for the study were analysed using both descriptive and inferential statistics. Data were collected on import, export and GDP and output of SMES from Central Bank of Nigeria statistical bulletin. The study used descriptive statistics, correction test and regression to study the variables. The study used descriptive statistics, correlation matrix, unit root test, cointegration and Vector Error Correction Model. The study used mean, median, skewness, kurtosis, standard deviation, maximum in value, minimum in value, Jarque-Bera, Probability and observation. The correlation coefficient is denoted by $r$ which indicates either -1 or +1 , showing the direction and degree of the linear association between variables. Variables may be positive or negative. The sign (positive and negative) of the correlation coefficient shows that the direction of the association between the variables.

To test the causality and co-integration between globalization and SMES performance, at first, the stationary properties of the time series is checked by unit root test using Dickey Fuller test, it is based on the following regression equation with a constant and a trend in the form as follows:

$$
\Delta \mathrm{Y}_{\mathrm{t}}=\beta_{1}+\beta_{2}+\delta \mathrm{Y}_{\mathrm{t}-1}+\alpha \mathrm{i} \sum_{i-1}^{M} \Delta \mathrm{Y}_{\mathrm{t}-1}+e j
$$

Where $\Delta$ is the first difference operator and $\varepsilon_{\mathrm{t}}$ is the stochastic error term and $\delta$ is the number of lags in the variable. The null hypothesis $\left(\mathrm{H}_{0}\right)$ of a unit root indicates that the coefficient of Yt-1 is zero while alternative hypothesis $\left(\mathrm{H}_{1}\right)$ implies Yt is stationary. If the null hypothesis is rejected then the series is stationary and no differencing in the series is essential to establish stationarity or the null hypothesis of nonstationary is rejected if the ADF test statistic in absolute term is more than the critical test value at 5\% level of significance.

The hypothesis of co-integration is accepted if the number of co- integrating relationships is greater than or equal to one. The decision rule compares the likelihood ratio to the critical value for a hypothesized number of co-integrating relationships. If the likelihood ratio is greater than the critical value, the hypotheses of co- integration is accepted, if not it is rejected. Globalization and SMEs performance for the period and if globalization is helpful in forecasting SMES performance, then the researcher may say that SMEs performance Granger-causes Globalization. However, if globalization causes SMEs performance and not versa vice, then the researcher may say there is unidirectional causality exists from FDI and government trade policy.

The study also noted if cointegration among variables solely shows a long run equilibrium relationship; in fact, there may be disequilibrium in the short run. To investigate the short run dynamics among the concerned time series variables, Vector Error Correction Model (VECM) is developed in this study. Vector Error Correction Model
(VECM) is used to correct the short-run disequilibrium among the variables in the model and also to reconfirm the direction of causality of the variables in the model.

The mathematical model of this study is stated below

$$
\mathrm{Y}=\mathrm{a}+\mathrm{bx}
$$

$\mathrm{y}=$ dependent variable

$\mathrm{a}=$ intercept or constant

$\mathrm{b}=$ the coefficient and

$\mathrm{x}=$ independent variable

However, this mathematical model is expressed as a functional model based on the objectives of this study. The study incorporated trade openness and SMEs output in Nigeria as showing below:

$$
\mathrm{TO}=\mathrm{f}(\text { SMEsopt })
$$

The model is also expressed as:

$$
\text { SMEsopt }=\text { F }(\mathrm{TO})
$$

All the series are expressed in a log- linear form in equation from $3 \& 4$ into equation 5 and 6 . This is an account that log linear specification provides consistent and reliable result (Schahbaz, Tang \&Shabbir, 2011). It is expressed as follows:

$$
\begin{aligned}
& \ln \mathrm{TO}=(\operatorname{lnSMEsopt}) \\
& \operatorname{lnSMEsopt}=(\ln \mathrm{TO})
\end{aligned}
$$

Using the above models, the Vector Error Correction Model specifications for hypothesis one are presented below:

$$
\begin{gathered}
\operatorname{lnTO}=\alpha_{0}+\alpha_{1} \Delta \operatorname{lnTO}+\alpha_{2} \operatorname{lnSMESopt}_{t-i}+E c t-1+\varepsilon_{t 1} \\
\operatorname{lnSMEsopt}=\alpha_{0}+\alpha_{1} \Delta \operatorname{lnSMESopt}+\alpha_{2} \operatorname{lnTO}_{t-i}+E c t-1+\varepsilon_{t 1}
\end{gathered}
$$

\section{Data Analysis and Discussion}

Table 1. Descriptive Statistics.

\begin{tabular}{lll}
\hline & SMESOPT & TO \\
\hline Mean & 2249354. & 0.332500 \\
Median & 137196.8 & 0.350000 \\
Maximum & 9764836. & 0.590000 \\
Minimum & 12322.40 & 0.070000 \\
Std. Dev. & 3146131. & 0.112135 \\
Skewness & 1.072279 & -0.122171 \\
Kurtosis & 2.765847 & 2.955189 \\
Jarque-Bera & 6.205275 & 0.082281 \\
Probability & 0.094931 & 0.959694 \\
Sum & 71979338 & 10.64000 \\
Sum Sq. Dev. & $3.07 \mathrm{E}+14$ & 0.389800 \\
Observations & 32 & 32 \\
\hline
\end{tabular}

Source: E-Views 9.0 Output, 2019.

The table showed that small and medium Scale output in Nigeria (SMEsopt) has a mean value (average) of 2249354 over the period of review. The table revealed that median value of 37196.8 which showed that the absence of outliers in the values. It has a maximum value of 9764836 which was 
obtained in the year 2015 before Nigerian Government experience economic recession. It also has a minimum value of 12322.40; it was obtained in the year 1986, due to Structural Adjustment Programme. The variable has a standard deviation of 3146131 which suggested that the value of the observation was spread across its mean value of 2249354. The skewness statistics of the variable was 1.07 , suggesting that was positive, while the kurtosis statistics of 2.76 suggested that the observation was leptokurtic in distribution. The Jaque-Bera statistics 6.20 with a probability value of 0.09 suggested that the SMEsoptwas normally distributed at $5 \%$ level of significance.

The table showed that trade openness (TO) has a mean value (average) of 0.332500 over the period of review. The table revealed that median value of 0.350000 which showed that the absence of outliers in the values. It has a maximum value of 0.590000 which was obtained in the year 1995. It also has a minimum value of 0.070000 ; it was obtained in the year 1986, due to Structural Adjustment Programme. The variable has a standard deviation of 0.172135 which suggested that the value of the observation was spread across its mean value of 0.332500 . The skewness statistics of the variable was -0.122171 , suggesting that wasnegative, while the kurtosis statistics of 2.955189 suggested that the observation was leptokurtic in distribution. The Jaque-Bera statistics 0.08 with a probability value of 0.95 suggested that the TO was normally distributed at $5 \%$ level of significance.

Table 2. Correlation Matrix between TO and SMEsopt.

\begin{tabular}{lll}
\hline & TO & SMEsopt \\
\hline TO & 1.000000 & \\
SMESopt & 0.525912 & 0.342530 \\
\hline
\end{tabular}

Source: Researcher's computation using, E-views 9.0, 2018.

Table 2 revealed that trade openness (TO), has strong positive correlation (0.52) with SMEs output (SMEsopt) in Nigeria. This correlation showed that the indicantwas appropriately selected. Thus, there was absent of multicollinearity or there was no problem of multicollinearity.

Table 3. Unit Root Test on the Variables.

\begin{tabular}{llllll}
\hline Variables & Level of stationarity & ADF-statistic & Significant values 1\%, 5\%, 10\% & Order of Integration & Prob. (5\%) \\
\hline LSMEsopt & constant (exogenous): Trend & 5.02 & $-4.28-3.56,-3.21$ & $1(1)$ & $0.0000 *$ \\
LTO & constant (exogenous): Trend & 4.59 & $-3.66,-2.96,-2.61$ & $1(1)$ & $0.0000 *$ \\
\hline
\end{tabular}

Source: Author's Computation using E-view 9.00. Probability values are indicated by *.

Table 3 showed that LSMEsoput and LTO were not stationary at level and second difference but stationary at first difference due to the fact that the values of its ADF test statistics at first differences were greater than their corresponding critical values at $5 \%$ level of significance.
Thus, LSMEsoput and LTO were stationary at first difference. Also, the variables were integrated of order one 1 (1) which signify that cointegration test, granger test and vector Error Correction Model test were appropriately and adequately needed in this study.

Table 4. Cointegration Results between Trade Openness and SMEs output in Nigeria.

\begin{tabular}{lllll}
\hline Variables & Trace Stat & Critical Value & Max-Eigen Stat & Critical Value \\
\hline LSMEsopt\& LTO & 18.86019 & 15.49471 & 15.91250 & 14.26460 \\
\hline
\end{tabular}

Source: Researchers computation using E-views 9.0, 2019.

Table 4 revealed Johansen and Josulius co-integration test and the test also revealed that there was a long-run relationship between the variables at $5 \%$ level of significance. The outcome of the Trace test statistic revealed that there were two cointegrating equation at 5\% level of significance for LSMEsopt \& LTO. Similarly, the result of the Max-Eigen test also revealed that there was two co-integrating equation at $5 \%$ level of significance for LSMEsopt \& LTO. Therefore, there was a long-run relationship between Trade Openness and SMEs output in Nigeria.

Causal Relationship between Trade Openness and SMEs output in Nigeria.

Table 5. Vector Error Correction Model.

\begin{tabular}{lll}
\hline Error Correction: & D (LSMEsopt) & D (LTO) \\
\hline CointEq1 & -0.092186 & $-1.26 \mathrm{E}-08$ \\
Standard Error & $(0.13979)$ & $-(4.4 \mathrm{E}-09)$ \\
t-statistics & {$[-0.65945]$} & {$[2.83766]$} \\
\hline
\end{tabular}

Causality: Causality runs from LTO to LSMEsopt.

Source: Researcher's computation using E-views 9.0, 2019.
Table 5 indicated that about $9 \%$ of short run disequilibrium was corrected by Small and medium scale output in Nigeria (LSMEsopt) in each period. It also revealed that $1.6 \%$ of short run disequilibrium was corrected by Trade Openness in each period. It also revealed $t$-statistics with their respective standard error values which implied that when the t-statistics in one variable was greater than the other variables numerically (the sign is not relevant), it means that causality move from that variable to the other variable and the direction of causality can be determined by comparing the tstatistic of the two variables.

From the table, the study found that causality runs from LTO to LSMEsopt which implied that Trade Openness caused increase in the inflow of SMEs output in Nigeria. This implied that Trade Openness attract more increase in SMEs output in Nigeria.

\section{Discussion of Findings}

The study found that that trade openness attracted or 
influence small and medium scale enterprise performance in Nigeria. This implied that trade openness affect small and medium scale enterprise output in Nigeria. The reason for this was that trade openness influences small and medium scale enterprises by ensuring that small and medium scale enterprises can produce goods and service by engaging in import and export so thmat the sector can be develop. The study is in line with the finding of Dotun et al (2018) and who found that causality runs unidirectional from trade openness to SMES performance. The study is also in tandem with Trans-formationalism Theory.

\section{Conclusion and Recommendation}

The study concluded that trade openness is an indispensable enabler of SMEs performance by increasing SMEs output. Trade openness provides new market opportunities for domestic firms (SMEs), stronger productivity, and innovation through competition. It contributes to poverty reduction, stronger wages, geopolitical benefits derived from deeper economic integration, and even on the personal level-increased individual choice and freedom of business. No country has developed successfully in modern times without harnessing economic openness- to international trade, investment, and the movement of people. The study therefore recommended that government of Nigeria should encourage import and export of small and medium scale products and service across board and they should place little or no restriction on SMEs product in order to encourage the SMEs output growth in Nigeria.

\section{References}

[1] Adewuyi, A. O. (2004). Can Nigeria benefit from globalization? Constraints, opportunities and challenges. Nigeria economic society.

[2] Anwar, A. S. G. S., Khalid, H. S., Tariq, M., Tahira, A. \& Faiz, M. S. (2011). Impact of Globalization on SMEs Export Business and Economy of Pakistan by Using CGE Model. Asian Social Science, 7 (9).

[3] Bakare A. S. \& Fawehinmi F. O. (2011). An econometric study of the contribution of oil sector to the standard of living in Nigeria: 1975-2008. Asian Journal of Business and Management Sciences, 1 (3) 01-08.

[4] Baldwin, R. E. (2000): "Trade and growth: still disagreement about the relationships", OECD Economics, Department Working Paper No\#. 264. OECD Economics Department.

[5] Big Ben, B. (2008). Current World Trade Agenda: GATT, Regionalism, and Unresolved Asymmetry Problems. Fordham L. Rev., 62, 2001.

[6] Dickson, M., Alick, B., Christopher, C. \& Douglas, K. (2018). The Impact of Globalization on SMEs in Emerging Economies: A Case Study of Zambia. International Journal of Business and Social Science, 9 (3).

[7] Dollar, D. \& Kraay, A. (2001). Growth is good for the poor. World Bank Policy Research Paper No 2587.
[8] Dotun, O. F. \& Angela, N. A. (2018). Trade Openness and Innovative Performance of Small and Medium Scale Enterprises: The Story of Nigeria and Ghana. European Journal of Business and Management, 10 (12).

[9] Igudia, P (2004) "Globalization and Economic Development: Nigeria's Experience and Prospects", Globalization and Africa's Economic Development, Ibadan: Nigerian Economic Society, pp: 347-375.

[10] Kandiero, N. \& Wadhawan, U. (2003). Economic Globalization and Institutions of Global Governance. International Journal of Business Management, 23 (2) 22-34.

[11] Karen, M. (2011). International Trade Openness in Turkey (19967-1997). Dogus Universitesi, 7: 86-98.

[12] Kohut, A., \& Wike, R. (2008) Assessing Globalization: Benefits and Drawbacks of Trade and Integration. Harvard International Review, 70-74.

[13] Kwatiu, W. (2007). Universalistic perspective of HRM and organizational performance: meta-analytical study. International Bulletin of Business Administration, 13.

[14] Ndungu, E. W. (2014). Influence of Globalization on Performance ofsmall And Medium Sized Enterprises in The Ict Sector in Kenya. University of Nairobi.

[15] Oladimeji, M. S., Ebodaghe, A. T.\& Shobayo, P. B. (2017). Effect of globalization on small and medium enterprises (smes) performance in Nigeria. International Journal of Entrepreneurial Knowledge, 2 (5).

[16] Oyedele, O. Thompson, S. \& Akanbi, F. K. (2016). Globalization and Small and Medium Enterprises Development in Nigeria: Evidence from Lagos, Nigeria. International Journal of Economics and Business Management, 2 (4).

[17] Obioma, S. \& Ozughalu, Y. (2005). "Effect of trade liberalization: looking at the evidence", Economic and Political Weekly, 3 (1) 4059-4067.

[18] QccQaier, Ali, Hafiz \& Muhammed, E. (2011). Trade and growth: import-led or export-led? Evidence from Japan and Korea.

[19] Samad, N. (2007). Positioning Malaysian SMEs in the global. Proceedings of Persidangan Kebangsaan IKS.

[20] Subhan, Q. A., Mehmood, M. R., \& Sattar, A. (2013). Innovation in Small and Medium Enterprises (SME's) and its impact on Economic Development in Pakistan. Paper presented at the Paper was presented in 6th International Business and Social Sciences Research Conference.

[21] Stwart, G. (2005). Performance implications of business strateg yand strategic behavior. Journal of marketing, 69 (3), 49-65.

[22] Tonia, K. \& Margaret, C. (2006). Trade Openness and Foreign Direct Investment in Africa. Global Development Policy, National Treasury, 3 (1) 44-56.

[23] Todaro, M. P. \& Smith, S. C. (2011). Economic Development, 12th Edition, Delhi: Pearson Education.

[24] Udo, F. (2014). Openness and economic growth: An empirical investigation. Applied Economics Letters, 6 (9) 557-561.

[25] World Bank (2013). Global Economic Prospects and Developing Countries, Washington D. C, USA. 